\title{
A New Ranking of Environmental Performance Index Using Weighted Correlation Coefficient in Intuitionistic Fuzzy Sets: A Case of ASEAN Countries
}

\author{
Lazim Abdullah $^{1} \&$ Wan Khadijah Wan Ismail ${ }^{1}$ \\ ${ }^{1}$ Faculty of Science and Technology, University Malaysia Terengganu, Kuala Terengganu, Malaysia \\ Correspondence: Lazim Abdullah, Faculty of Science and Technology, University Malaysia Terengganu, Kuala \\ Terengganu 21030, Terengganu, Malaysia. Tel: 60-9-668-3335. E-mail: lazim_m@umt.edu.my
}

Received: March 21, 2013

Accepted: April 5, $2013 \quad$ Online Published: May 14, 2013

doi:10.5539/mas.v7n6p42

URL: http://dx.doi.org/10.5539/mas.v7n6p42

\begin{abstract}
Growth in number of population and development nowadays indicate a good sign for nation's development. However, the development sometimes might neglects the preservation and conservation of nature and can reflects in environment performance. Concerning on this matters, Environmental Performance Index (EPI) has been introduced since 2006 to depict the environment performance for most of the countries in the world. The index considers ten policy categories associated with environmental public health and ecosystem sustainability. The main mathematics operation in establishing EPI is arithmetic mean of all ten policy categories. One of the weaknesses in the arithmetic mean is the operation might neglects some extreme values in data. Recently, Wan Ismail and Abdullah introduced the EPI using analytic hierarchy process (AHP) but the weight of policy category was not considered. This paper proposes a new ranking of EPI using a decision making tool of weighted correlation coefficient based on intuitionistic fuzzy sets (IFS). An original data of policy categories were converted into IFSs which benefiting in considering two-sided of membership and non membership. Criteria weights for alternatives in fuzzy correlation coefficient were utilized to set new EPI for nine ASEAN countries. A new ranking EPI among ASEAN countries show that Thailand is the highest EPI followed by Malaysia. The new ranking may offer an alternative measure in evaluating environmental performance particularly for ASEAN countries.
\end{abstract}

Keywords: environmental sustainability, environmental performance index, intuitionistic fuzzy sets, weighted correlation coefficient

\section{Introduction}

Sustainable development can be defined generally as the situation when development and preservation on environment get balance. However, other issues like economy sustainability and socio-political sustainability are not neglected. There are many types of sustainable development such as environmental sustainability, economical sustainability, socio-political sustainability, ecological sustainability and cultural sustainability. Environmental sustainability is a process to make sure that the daily life activities and any usage of environment is friendly environmental and preserved environment. An unsustainable environment is the situation where the usage and development does not preserve the environment and the nature's source had been used is more than the replenished. The widely method used to assess the environmental sustainability are Emergy Evaluation (EME) and Ecological Footprint Analysis (EFA). The outcomes of the assessment are focused on resources depletion, consumption patterns, waste production and absorption (Marchetinni et al., 2007). Environmental impact is measured by the emergy investment ratio defined as the ratio of the emergy purchased from the economy divided by the emergy from the local environment (Odum, 1998). Ecological footprint analysis compares human demand on nature with the biosphere's ability to regenerate resources and provide services. It is done by assessing the biologically productive land and marine area required to produce the resources a population consumes and absorb the corresponding waste using prevailing technology (Eco Greenwares, 2009). Per capita ecological footprint (EF) is comparing consumption and lifestyles and checking this against nature's ability to provide for this consumption (Cui \& Yu, 2009).

Performance in handling environmental policy categories is another perspective in environmental assessment. 
Environmental Performance Index (EPI) which ranks 132 countries on ten policy categories covering both environmental public health and ecosystem vitality is one of the popular measures in assessing environmental performance of a country. This index had been conducted by The Yale Center for Environmental Law and Policy (YCELP) and the Center for Earth Information Science Information Network (CIESIN) at Columbia University. These indices provide a gauge at a national government scale on how close countries are to established environmental policy goals (Yale Center for Environmental Law and Policy and Center for International Earth Science Information Network, 2012). Each policy categories is made up of one or more environmental indicators. For each country and indicator, a proximity-to-target value is calculated based on the gap between a country's current result and the policy target. The generic formula for the proximity-to-target in the context of the global EPI is calculated using the following distance to target formula.

$$
\text { ((international range) - (distance to target) / (international range) x } 100
$$

The EPI is based on a proximity-to-target methodology whereby each country's performance on any given indicator is measured based on its position within a range established by the lowest performing country, equivalent to 0 on a $0-100$ scale and the target, equivalent to 100 . The illustration of methodology is shown in Figure 1. The words "Better" and "Worse" are relative terms and refer to the distance to the target.

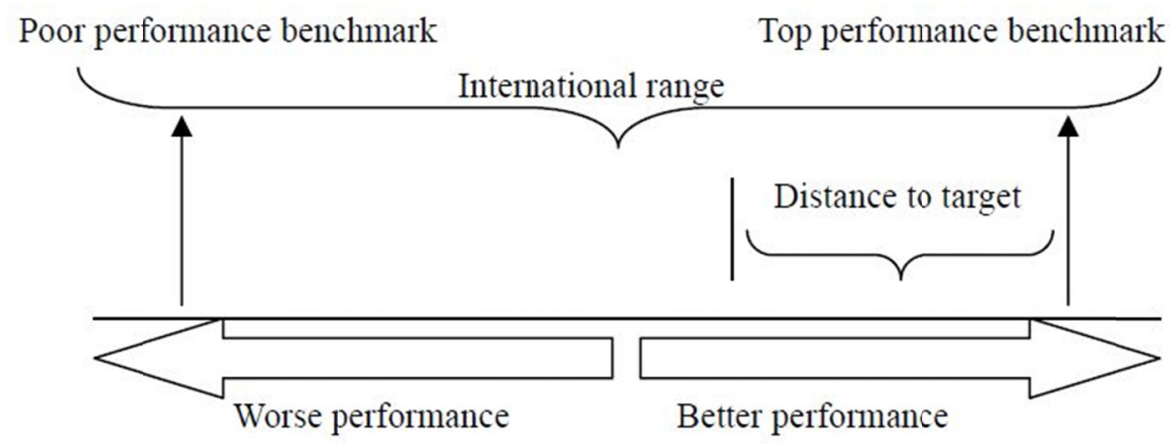

Figure 1. Framework of proximity-to-target methodology (Emerson et al., 2012)

All values of proximity-to-target indicators were summed and averaged. Data selection was made from official statistics reported by governments, spatial data, observing from monitoring stations and from modelled data (Emerson et al., 2012). It can be seen that EPI use a simple average calculation thereby may neglect some extreme values in the data.

With the advent of computing based technology, Liqian and Jianming (2012) conducted an eco-environmental quality assessment of Xining city based on geographic information system (GIS) and analytic hierarchy process (AHP). The assessment result marks with colours using GIS, which show the qualities; red for stop and green for pass. Also, the assessment conducted ranked the factors influenced the eco-environment in Xining area using weight obtained in AHP. Social cycle is a dominant factors eco-environment in Xining area followed by hydrosphere, atmosphere, lithosphere and biosphere. Assessment of environmental issues was also gained attention by intelligent methods based on fuzzy sets theory. Silvert (2000), for example, found that fuzzy logic can be used to classify and quantify environmental effects of a subjective nature, such as bad odours and it even provides formalism for dealing with missing data. The fuzzy memberships not only can be used as environmental indices but it is also possible to obtain a more traditional type of index through defuzzification. The fuzzy methodology also used to evaluate of the effects of finfish mariculture on coastal zone water quality. In line with the development of fuzzy sets theory, the dual assessment concept intuitionistic fuzzy sets were hybridized with AHP. This integrated approach which later known as IF-AHP was meant to handle both vagueness and ambiguity related uncertainties in the environment decision-making process. Sadiq and Tesfamariam (2009) used IF-AHP methodology to select best drilling fluid (mud) for drilling operations under multiple environmental-based criteria like air emissions, spills, water column, bioaccumulation, benthic effects, air emission and ground water contamination.

In another attempt to further proliferate the AHP in environmental assessment, Wan-Ismail and Abdullah (2012) proposed a new environmental index. The method used pair wise comparison scale in analytic hierarchy process to set a new EPI for ASEAN countries. A comparison scale was given using a pair-wise comparison scale for AHP preference introduced by Saaty and Windy (1980). A weight of each policy category was considered as an important element prior to proposing overall index. Despite this success, the AHP has its own weaknesses. While 
using AHP, the decision problem is decomposed into a number of subsystems in which substantial number of pair wise comparisons need to be completed. Number of pair wise comparisons to be made may become very large depending on the size of matrix. The relation $(\mathrm{n}(\mathrm{n}-1) / 2)$ where $\mathrm{n}$ is size of decision matrix clearly lead to a lengthy task (Macharis et al., 2004). Another disadvantage of the AHP method is the artificial limitation of the use of the 9-point scale. Sometimes the decision maker might find difficult to distinguish among them. Also, the AHP method cannot cope with the fact that an alternative is 25 times more important than another alternative (Belton \& Gear, 1983; Belton, 1986).

As an effort to overcome these weaknesses, a new approach in calculating environmental performance index is proposed. The proposed method for measuring environmental performance is taken into account weight of each policy category. The method was originally proposed by Ye (2010) as a method in fuzzy decision-making method based on the weighted correlation coefficient. To the best of authors' knowledge, this dual assessment method has not been tested to environmental performance. The weight of each policy category and two-sided memberships of intuitionistic fuzzy sets (IFSs) is considered as an important characteristic in this calculation. The aim of this paper is to propose weights for policy categories and subsequently propose a new rank of EPI. Nine ASEAN countries are tested to the weighted correlation coefficient method as an alternative method in calculating new EPI. The paper unfolds as follows. The next section briefly introduces some definitions related to the method. Section 3 describes the weighted correlation coefficient in IFSs proposed by Ye (2010). Section 4 presents weights for policy categories and a new ranking of EPI. Discussions section presents a new ranking of EPI. A comparison between original EPI and related study is made in this section. Conclusions appear in the last section.

\section{Preliminaries}

This section introduces some definitions that self-contained to the paper.

Definition 1 Fuzzy set theory (Zadeh, 1965).

A fuzzy set theory $A$ in the universe of discourse $X=\left\{x_{1}, x_{2}, \ldots, x_{n}\right\}$ is defined as:

$$
A=\left\{<x, \mu_{A}(x)>\mid x \in X\right\},
$$

which is characterized by membership function $\mu_{A}(x): X \rightarrow[0,1]$, where $\mu_{A}(x)$ indicates the membership degree of the element $x$ to the set $A$.

Definition 2 Intuitionistic fuzzy sets (Atanassov, 1986).

An IFS in $X$ is an expression $A$ is defined by

$$
A=\left\{<x, \mu_{A}(x), v_{A}(x)>\mid x \in X\right\},
$$

where $\mu_{A}(x): X \rightarrow[0,1]$ and $v_{A}(x): X \rightarrow[0,1]$, with the condition $0 \leq \mu_{A}(x)+v_{A}(x) \leq 1$. The numbers $\mu_{A}(x)$ and $v_{A}(x)$ represent respectively the membership degree and non-membership degree of the element $x$ to the set $A$. For each IFS in $X$ :

$$
\pi_{A}(x)=1-\mu_{A}(x)-v_{A}(x)
$$

for all $x \in X$. Then $\pi_{A}(x)$ is called the intuitionistic index or hesitancy degree of the element $x$ in the set $A$. It can be seen that $0 \leq \pi_{A}(x) \leq 1, x \in X$.

For two IFS $A=\left\{<x, \mu_{A}(x), v_{A}(x)>\mid x \in X\right\}$ and $B=\left\{<x, \mu_{B}(x), v_{B}(x)>\mid x \in X\right\}$ the two relations are follows:

$$
\begin{aligned}
& A \subseteq B \text { if and only if } \mu_{A}(x) \leq \mu_{B}(x) \text { and } v_{A}(x) \leq v_{B}(x) \text { for any } x \in X ; \\
& A=B \text { if and only if } \mu_{A}(x)=\mu_{B}(x) \text { and } v_{A}(x)=v_{B}(x) \text { for any } x \in X .
\end{aligned}
$$

Definition 3 Correlation coefficient of IFSs (Gerstenkorn \& Manko, 1991)

Let $A$ and $B$ be two IFSs in the universe of discourse $X=\left\{x_{1}, x_{2}, \ldots, x_{n}\right\}$. The correlation coefficient of $A$ and $B$ is given by

$$
k(A, B)=\frac{C(A, B)}{\sqrt{T(A) \cdot T(B)}},
$$

where the correlation of two IFSs $A$ and $B$ is given by $C(A, B)=\sum_{i=1}^{n}\left(\mu_{A}\left(x_{i}\right) \mu_{B}\left(x_{i}\right)+v_{A}\left(x_{i}\right) v_{B}\left(x_{i}\right)\right)$ and the informational intuitionistic energies of 
two IFSs $A$ and $B$ are given by $T(A)=\sum_{i=1}^{n}\left(\mu_{A}^{2}\left(x_{i}\right)+v_{A}^{2}\left(x_{i}\right)\right)$ and $T(B)=\sum_{i=1}^{n}\left(\mu_{B}^{2}\left(x_{i}\right)+v_{B}^{2}\left(x_{i}\right)\right)$, respectively. The correlation coefficient of two IFSs $A$ and $B$ satisfies the following properties:

(1) $0 \leq k(A, B) \leq 1$,

(2) $k(A, B)=k(B, A)$,

(3) $k(A, B)=1$ if $A=B$.

Definition 4 Intuitionistic entropy of IFSs (Burillo \& Bustince, 1996)

Let $A$ be an IFS in the universe of discourse $X=\left\{x_{1}, x_{2}, \ldots, x_{n}\right\}$. The intuitionistic fuzzy entropy of an IFS $A$ is defined as follows:

$$
E(A)=\sum_{i=1}^{n}\left(1-\mu_{A}\left(x_{i}\right)-v_{A}\left(x_{i}\right)\right)=\sum_{i=1}^{n} \pi_{A}\left(x_{i}\right) .
$$

\section{Method and Material}

\subsection{Weighted Correlation Coefficient (Ye, 2010)}

Based on the correlation coefficient between IFSs proposed by Gernstenkorn and Manko (1991), the correlation coefficient between an alternative $A_{\mathrm{i}}$ and the ideal alternative $A^{*}$ with entropy weights for criteria can be measured by the weighted correlation coefficient $W_{i}(i=1,2, \ldots, m)$

$$
W_{i}\left(A^{*}, A_{i}\right)=\frac{\sum_{j=1}^{n} w_{j} \mu_{A}\left(C_{j}\right)}{\sqrt{\sum_{j=1}^{n} w_{j}\left(\mu_{A_{i}}^{2}\left(C_{j}\right)+v_{A_{i}}^{2}\left(C_{j}\right)\right)}} .
$$

If the information about weight $w_{j}$ of the criterion $C_{j}(j=1,2, \ldots, n)$ is completely unknown, then the model of entropy weights is applied to determine the criteria weight:

$$
w_{j}=\frac{1-H_{j}}{n-\sum_{j=1}^{n} H_{j}}
$$

where $w_{j} \in[0,1], \sum_{j=1}^{n} w_{j}=1, H_{j}=\frac{1}{m} E\left(C_{j}\right)=\frac{1}{m} \sum_{i=1}^{m}\left(1-\mu_{A_{i}}\left(C_{j}\right)-v_{A_{i}}\left(C_{j}\right)\right)=\frac{1}{m} \sum_{i-1}^{m} \pi_{A}\left(C_{j}\right)$ and $0 \leq H_{j} \leq 1$ for $(j=1,2, \ldots, n)$.

The larger the value of weighted correlation coefficient $W_{i}$, the better alternative $A_{i}$, as the alternative $A_{i}$, is closer to the alternative $A^{*}$. Therefore, all the alternatives can be ranked according to the weighted correlation coefficients so that the best alternatives can be selected. The weighted correlation coefficient $W_{i}(i=1,2, \ldots, m)$ of $A_{\mathrm{i}}$ and $A^{*}$ have the following properties:

(1) $0 \leq W_{i}\left(A^{*}, A_{i}\right) \leq 1$,

(2) $W_{i}\left(A^{*}, A_{i}\right)=W_{i}\left(A_{i}, A^{*}\right)$,

(3) $W_{i}\left(A^{*}, A_{i}\right)=1$ if $A^{*}=A_{i}$.

\subsection{Environmental Performance Index 2012}

Environmental Performance Index 2012 and ranking issued by Yale Center for Environmental Law and Policy and Center for International Earth Science Information Network (2012) among nine ASEAN countries are given in Table 1. Nine ASEAN countries are indicated as Ai (i=1, 2, 3, 4, 5, 6, 7, 8, 9). 
Table 1. Environmental performance index (EPI) 2012

\begin{tabular}{ccc}
\hline Ranking & Countries $\left(A_{\mathrm{i}}\right)$ & EPI Score \\
\hline 1 & Malaysia $\left(A_{1}\right)$ & 62.5 \\
2 & Brunei $\left(A_{2}\right)$ & 62.5 \\
3 & Thailand $\left(A_{3}\right)$ & 60.0 \\
4 & Philippines $\left(A_{4}\right)$ & 57.4 \\
5 & Singapore $\left(A_{5}\right)$ & 56.4 \\
6 & Cambodia $\left(A_{6}\right)$ & 55.3 \\
7 & Myanmar $\left(A_{7}\right)$ & 52.7 \\
8 & Indonesia $\left(A_{8}\right)$ & 52.3 \\
9 & Vietnam $\left(A_{9}\right)$ & 50.6 \\
\hline
\end{tabular}

Data of the ten policy categories, $c_{\mathrm{i}}(\mathrm{i}=1,2,3,4,5,6,7,8,9,10)$ were retrieved as secondary data in proposing a new ranking of EPI. Environmental burden of disease, air pollution (impact on humans), water (impact on humans), air pollution (impact on ecosystem), water (impact on ecosystem), biodiversity, forestry, fisheries, agriculture and climate change were the nine policy categories. Table 2(a) and 2(b) shows the data for ASEAN countries extracted from Yale Center for Environmental Law and Policy and Center for International Earth Science Information Network (2012).

Table 2(a). Index each policy categories

\begin{tabular}{lccccc}
\hline $\begin{array}{l}\text { ASEAN } \\
\text { Countries }\end{array}$ & $\begin{array}{c}\text { Environmental } \\
\text { Burden of } \\
\text { Disease, } c_{1}\end{array}$ & $\begin{array}{c}\text { Air Pollution } \\
\text { (impact on } \\
\text { humans), } c_{2}\end{array}$ & $\begin{array}{c}\text { Water Pollution } \\
\text { (impact on } \\
\text { humans), } c_{3}\end{array}$ & $\begin{array}{c}\text { Air Pollution } \\
\text { (impact on } \\
\text { ecosystem), } c_{4}\end{array}$ & $\begin{array}{c}\text { Water Pollution } \\
\text { (impact on } \\
\text { ecosystem), } c_{5}\end{array}$ \\
\hline Malaysia & 80.6 & 97.3 & 82.6 & 41.5 & 48.4 \\
Brunei & 86.4 & 100.0 & 38.2 & 37.1 & 99.6 \\
Thailand & 87.6 & 40.3 & 70.0 & 42.9 & 18.2 \\
Philippines & 58.0 & 55.4 & 38.9 & 39.1 & 36.4 \\
Singapore & 100.0 & 100.0 & 100.0 & 31.2 & 14.5 \\
Cambodia & 35.7 & 42.0 & 11.6 & 64.4 & 45.3 \\
Myanmar & 40.7 & 33.8 & 28.7 & 70.2 & 50.9 \\
Indonesia & 57.7 & 54.3 & 23.1 & 38.9 & 46.7 \\
Vietnam & 42.5 & 31.0 & 42.5 & 43.8 & 37.8 \\
\hline
\end{tabular}

Table 2(b). Index each policy categories (continuation from Table 2(a))

\begin{tabular}{lccccc}
\hline $\begin{array}{l}\text { ASEAN } \\
\text { Countries }\end{array}$ & Biodiversity, $c_{6}$ & Forestry, $c_{7}$ & Fisheries, $c_{8}$ & Agriculture, $c_{9}$ & $\begin{array}{c}\text { Climate } \\
\text { Change, } c_{10}\end{array}$ \\
\hline Malaysia & 90.1 & 17.4 & 31.0 & 95.5 & 28.0 \\
Brunei & 90.7 & 66.7 & 67.6 & 44.2 & 5.2 \\
Thailand & 78.9 & 87.0 & 34.2 & 93.9 & 39.2 \\
Philippines & 66.0 & 90.1 & 25.8 & 92.4 & 64.7 \\
Singapore & 34.1 & 79.4 & 18.4 & 98.5 & 28.3 \\
Cambodia & 94.8 & 28.3 & 21.6 & 66.7 & 73.9 \\
Myanmar & 53.6 & 26.3 & 33.3 & 84.8 & 77.3 \\
Indonesia & 75.3 & 54.7 & 38.1 & 54.6 & 48.9 \\
Vietnam & 54.1 & 81.4 & 19.4 & 47.8 & 56.5 \\
\hline
\end{tabular}

The index for each policy category shall be converted into intuitionistic fuzzy sets (IFSs) notation to fit with the weighted correlation coefficient formula. 


\subsection{Computational Method}

The summary of computations procedure is given in Figure 2.

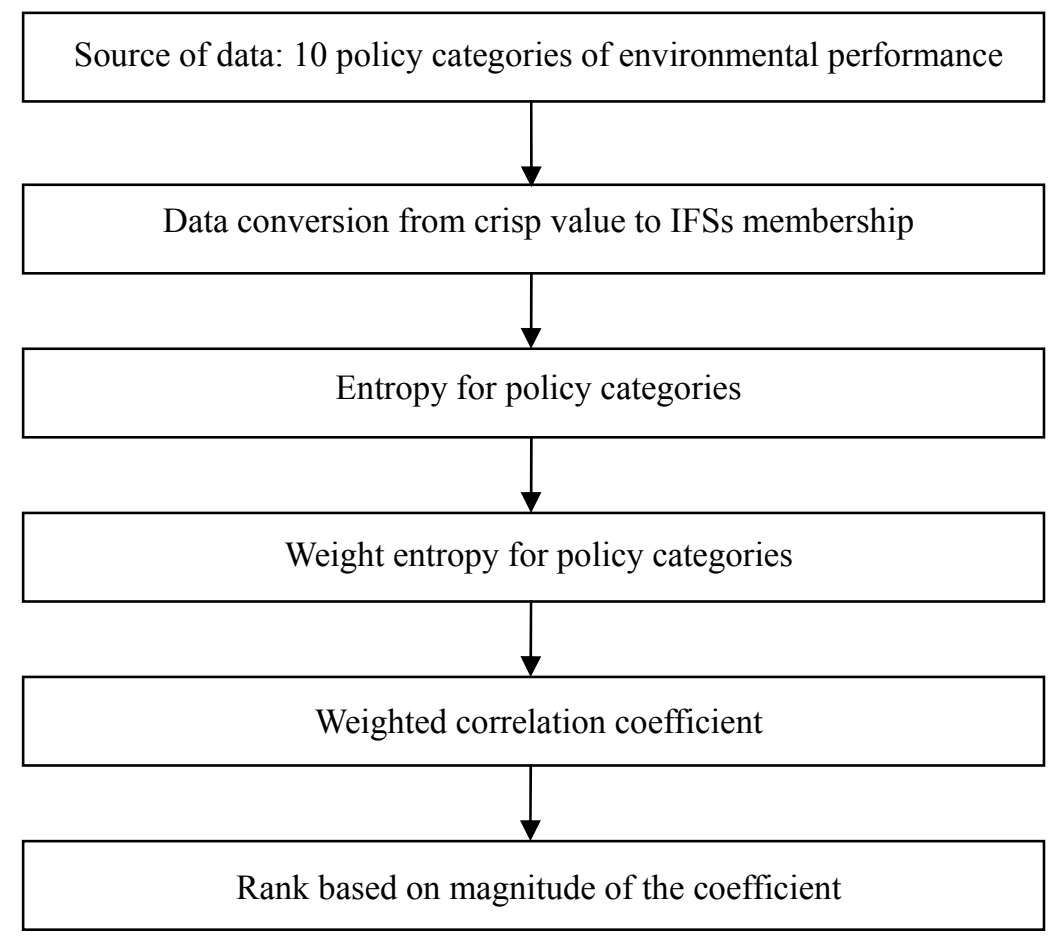

Figure 2. Flows of the computation

The computational framework is implemented with the data of policy categories of environmental performance.

\section{Implementation and Results}

The process of calculating the weighted correlation coefficient for ASEAN countries can be divided into two phases. The first phase is converting the entire index for policy categories into IFSs form. Then, in the second phase, weighted correlation coefficients of IFSs in ASEAN countries are calculated. A new ranking based on environmental performance can be obtained using the following steps:

Step 1 Convert to interpretation score, $\mu^{\prime \prime}(x)$.

Let's take data of Malaysia as an example in this calculation. The original data of environmental burden of disease policy category are converted to IFSs. Since the maximum value of is $100 \%$, then the interpretation score is $80.6 \%$ (see Table 2(a)).

Step 2 Determine the value of hesitation, $\pi(x)$.

Levels of consistency and membership grades in Table 3 are used to determine value of hesitation.

Table 3. Conversion of consistency expressions to membership grades (Hersh, 2006)

\begin{tabular}{lcc}
\hline Consistency & $\mu^{\prime \prime}(x)$ & $\pi(x)$ \\
\hline No or very low consistency & $0.0-0.2$ & $0.8-1.0$ \\
Low consistency & $0.2-0.4$ & $0.6-0.8$ \\
Moderate consistency & $0.4-0.6$ & $0.4-0.6$ \\
High consistency & $0.6-0.8$ & $0.2-0.4$ \\
Very high or total consistency & $0.8-1.0$ & $0.0-0.2$ \\
\hline
\end{tabular}

If the value of $\mu^{\prime \prime}(x)=1$ then $\pi(x)=0$ and if $\mu^{\prime \prime}(x)=0.9$ then $\pi(x)=0.1$. From Step $1, \mu^{\prime \prime}(x)=$ 0.806 , then hesitation value is 0.2 , in the level of very high consistency. 
Step 3 Calculate the value of membership, $\mu(x)$.

The value of membership, $\mu(x)$ is calculated using the equation $\mu(x)=\mu^{\prime \prime}(x)[1-\pi(x)]=0.806[1-0.2]=0.6448$.

Step 4 Calculate the value of non membership, $v(x)$.

The value of non membership, $v(x)$ calculate using Equation (3), $v(x)=1-\mu(x)-\pi(x)=1-0.6448-0.2=0.1552$.

Step 5 Arrange the memberships in the IFSs notation.

$$
\begin{aligned}
\mathrm{C}_{1} & =(\mu(\mathrm{x}), v(\mathrm{x}), \pi(\mathrm{x})) \\
& =(0.6448,0.1552,0.2)
\end{aligned}
$$

Memberships for other policy categories of ASEAN countries are calculated with the similar fashion. It is listed in Table 4(a), Table 4(b) and Table 4(c).

Table 4(a). IFS of policies for ASEAN countries

\begin{tabular}{lllll}
\hline Countries & $\begin{array}{l}\text { Environmental Burden } \\
\text { of Disease (DALYs), } c_{1}\end{array}$ & $\begin{array}{l}\text { Air Pollution (impact } \\
\text { on humans), } c_{2}\end{array}$ & $\begin{array}{l}\text { Water (impact on } \\
\text { humans), } c_{3}\end{array}$ & $\begin{array}{l}\text { Air Pollution (impact } \\
\text { on ecosystem), } c_{4}\end{array}$ \\
\hline Malaysia & $(0.6448,0.1552,0.2)$ & $(0.9730,0.0270,0.0)$ & $(0.6608,0.1392,0.2)$ & $(0.1660,0.2340,0.6)$ \\
Brunei & $(0.7776,0.1224,0.1)$ & $(1.0000,0.0000,0.0)$ & $(0.1528,0.2472,0.6)$ & $(0.1484,0.2516,0.6)$ \\
Thailand & $(0.7884,0.1116,0.1)$ & $(0.1612,0.2388,0.6)$ & $(0.4900,0.2100,0.3)$ & $(0.1716,0.2284,0.6)$ \\
Philippines & $(0.3480,0.2520,0.4)$ & $(0.3324,0.2676,0.4)$ & $(0.1556,0.2444,0.6)$ & $(0.1564,0.2436,0.6)$ \\
Singapore & $(1.0000,0.0000,0.0)$ & $(1.0000,0.0000,0.0)$ & $(1.0000,0.0000,0.0)$ & $(0.0936,0.2964,0.7)$ \\
Cambodia & $(0.1428,0.2572,0.6)$ & $(0.1680,0.2320,0.6)$ & $(0.0116,0.0884,0.9)$ & $(0.3864,0.2136,0.4)$ \\
Myanmar & $(0.1628,0.2372,0.6)$ & $(0.1014,0.1986,0.7)$ & $(0.0861,0.2139,0.7)$ & $(0.4914,0.2086,0.3)$ \\
Indonesia & $(0.3462,0.2538,0.4)$ & $(0.2715,0.2285,0.5)$ & $(0.0462,0.1538,0.8)$ & $(0.1556,0.2444,0.6)$ \\
Vietnam & $(0.1700,0.2300,0.6)$ & $(0.0930,0.2070,0.7)$ & $(0.1700,0.2300,0.6)$ & $(0.1752,0.2248,0.6)$ \\
\hline
\end{tabular}

Table 4(b). IFS of policies for ASEAN countries (continuation from Table 4(a))

\begin{tabular}{llll}
\hline Countries & Water (impact on ecosystem), $c_{5}$ & Biodiversity, $c_{6}$ & Forestry, $c_{7}$ \\
\hline Malaysia & $(0.2420,0.2580,0.5)$ & $(0.8109,0.0891,0.1)$ & $(0.0348,0.1652,0.8)$ \\
Brunei & $(0.9960,0.0040,0.0)$ & $(0.8163,0.0837,0.1)$ & $(0.4669,0.2331,0.3)$ \\
Thailand & $(0.0364,0.1636,0.8)$ & $(0.6312,0.1688,0.2)$ & $(0.7830,0.1170,0.1)$ \\
Philippines & $(0.1456,0.2544,0.6)$ & $(0.4620,0.2380,0.3)$ & $(0.8109,0.0891,0.1)$ \\
Singapore & $(0.0145,0.0855,0.9)$ & $(0.1023,0.1977,0.7)$ & $(0.6352,0.1684,0.2)$ \\
Cambodia & $(0.2265,0.2735,0.5)$ & $(0.8532,0.0468,0.1)$ & $(0.0849,0.2151,0.7)$ \\
Myanmar & $(0.2545,0.2455,0.5)$ & $(0.2680,0.2320,0.5)$ & $(0.0789,0.2211,0.7)$ \\
Indonesia & $(0.2335,0.2665,0.5)$ & $(0.6024,0.1976,0.2)$ & $(0.2735,0.2265,0.5)$ \\
Vietnam & $(0.1512,0.2488,0.6)$ & $(0.2705,0.2295,0.5)$ & $(0.6512,0.1488,0.2)$ \\
\hline
\end{tabular}


Table 4(c). IFS of policies for ASEAN countries (continuation from Table 4(c))

\begin{tabular}{llll}
\hline Countries & Fisheries, $c_{8}$ & Agriculture, $c_{9}$ & Climate Change, $c_{10}$ \\
\hline Malaysia & $(0.0930,0.2070,0.7)$ & $(0.9550,0.0450,0.0)$ & $(0.0840,0.2160,0.7)$ \\
Brunei & $(0.4732,0.2268,0.3)$ & $(0.1768,0.2232,0.6)$ & $(0.0052,0.0948,0.9)$ \\
Thailand & $(0.1026,0.1974,0.7)$ & $(0.8451,0.0549,0.1)$ & $(0.1568,0.2432,0.6)$ \\
Philippines & $(0.0774,0.2226,0.7)$ & $(0.8316,0.0684,0.1)$ & $(0.3882,0.2118,0.4)$ \\
Singapore & $(0.0368,0.1632,0.8)$ & $(0.9850,0.0150,0.0)$ & $(0.0849 .0 .2151,0.7)$ \\
Cambodia & $(0.0432,0.1568,0.8)$ & $(0.4669,0.2331,0.3)$ & $(0.5173,0.1827,0.3)$ \\
Myanmar & $(0.0999,0.2001,0.7)$ & $(0.6784,0.1216,0.2)$ & $(0.6184,0.1816,0.2)$ \\
Indonesia & $(0.1524,0.2476,0.6)$ & $(0.2730,0.2270,0.5)$ & $(0.2445,0.2555,0.5)$ \\
Vietnam & $(0.0388,0.1612,0.8)$ & $(0.2390,0.2610,0.5)$ & $(0.3390,0.2610,0.4)$ \\
\hline
\end{tabular}

Step 6 Calculate the weight of criteria.

Since the weight $w_{1}$ of the criterion $C_{j}(j=1,2,3,4,5,6,7,8,9,10)$ is completely unknown, the entropy weights are calculated using Equation (7).

$$
\begin{aligned}
& \mathrm{H}_{1}=\frac{1}{9}(0.2+0.1+0.1+0.4+0+0.6+0.6+0.4+0.6)=0.3333, \\
& \sum_{\mathrm{j}=1}^{10} \mathrm{H}_{\mathrm{j}}=\frac{1}{9} \mathrm{H}_{1}+\frac{1}{9} \mathrm{H}_{2}+\ldots+\frac{1}{9} \mathrm{H}_{10} \\
& =\frac{1}{9}(0.2+0.1+0.1+0.4+0+0.6+0.6+0.4+0.6)+\frac{1}{9}(0+0+0.6+0.4+0+0.6+0.7+0.5+0.7) \\
& +\ldots+\frac{1}{9}(0.7+0.9+0.6+0.4+0.7+0.3+0.2+0.5+0.4) \\
& =4.5,
\end{aligned}
$$

Weight of environmental burden of disease policy categories,

$$
\begin{aligned}
w_{1} & =\frac{1-0.3333}{10-4.5} \\
& =0.1212
\end{aligned}
$$

The calculation for other policy categories is executed in the similar fashion. The weights for all ten policy categories are obtained as,

$$
\begin{aligned}
& \mathrm{w}_{1}=0.1212, \mathrm{w}_{2}=0.1111, \mathrm{w}_{3}=0.0869, \mathrm{w}_{4}=0.0808, \mathrm{w}_{5}=0.0828, \\
& \mathrm{w}_{6}=0.1273, \mathrm{w}_{7}=0.1091, \mathrm{w}_{8}=0.0586, \mathrm{w}_{9}=0.1354, \mathrm{w}_{10}=0.0869 .
\end{aligned}
$$

Step 7 Calculate the weighted correlation coefficient.

The weighted correlation coefficient between an alternative $A_{\mathrm{i}}$ and the ideal alternative $A^{*}$ with entropy weights for criteria, $W\left(A^{*}, A_{i}\right)(i=1,2,3,4,5,6,7,8,9)$ is measured using Equation (6). The weighted correlation coefficient $W\left(A^{*}, A_{1}\right)$ is:

$$
\begin{aligned}
W_{i}\left(A^{*}, A_{1}\right) & =\frac{\sum_{j=1}^{10} w_{j} \mu_{A}\left(C_{j}\right)}{\sqrt{\sum_{j=1}^{10} w_{j}\left(\mu_{A_{i}}^{2}\left(C_{j}\right)+v_{A_{i}}^{2}\left(C_{j}\right)\right)}} \\
& =\frac{0.1212(0.6448)+0.1111(0.9730)+\ldots+0.0869(0.0840)}{\sqrt{0.1212\left(0.6448^{2}+0.1552^{2}\right)+0.1111\left(0.9730^{2}+0.0270^{2}\right)+\ldots+0.0869\left(0.0840^{2}+0.2160^{2}\right)}} \\
& =0.7983
\end{aligned}
$$

The calculation is executed to other eight countries. Weighted correlation coefficients are listed in Table 5. 
Table 5. Weighted correlation coefficient of ASEAN countries

\begin{tabular}{lcc}
\hline Countries $\left(A_{\mathrm{i}}\right)$ & $W\left(A^{*}, A_{\mathrm{i}}\right)$ & New Ranking \\
\hline Malaysia $\left(A_{1}\right)$ & 0.7983 & 2 \\
Brunei $\left(A_{2}\right)$ & 0.7969 & 3 \\
Thailand $\left(A_{3}\right)$ & 0.7994 & 1 \\
Philippines $\left(A_{4}\right)$ & 0.7778 & 4 \\
Singapore $\left(A_{5}\right)$ & 0.7680 & 5 \\
Cambodia $\left(A_{6}\right)$ & 0.6888 & 8 \\
Myanmar $\left(A_{7}\right)$ & 0.6937 & 7 \\
Indonesia $\left(A_{8}\right)$ & 0.7214 & 6 \\
Vietnam $\left(A_{9}\right)$ & 0.6569 & 9 \\
\hline
\end{tabular}

Table 5 shows the weighted correlation coefficients for each country. The larger value of weighted correlation coefficients indicates the better alternative in environmental performance.

\section{Discussion}

A new EPI ranking for ASEAN countries using weighted correlation coefficient is obtained. The new ranking was established after considering the weights in each policy category. The membership and non-membership values in IFSs are the main characteristics prior to introducing the weights. The memberships are embedded with fuzzy correlation coefficient to find the best alternatives. The best alternative represents the better country in environmental performance.

The results show that Thailand leads in the first place followed by Malaysia and Brunei while the last three countries are Myanmar, Cambodia and Vietnam. The obtained ranking is illustrated and compared with the original EPI 2012 and EPI 2012 using AHP. The new ranking and ranking from the other two methods are illustrated in Figure 3.

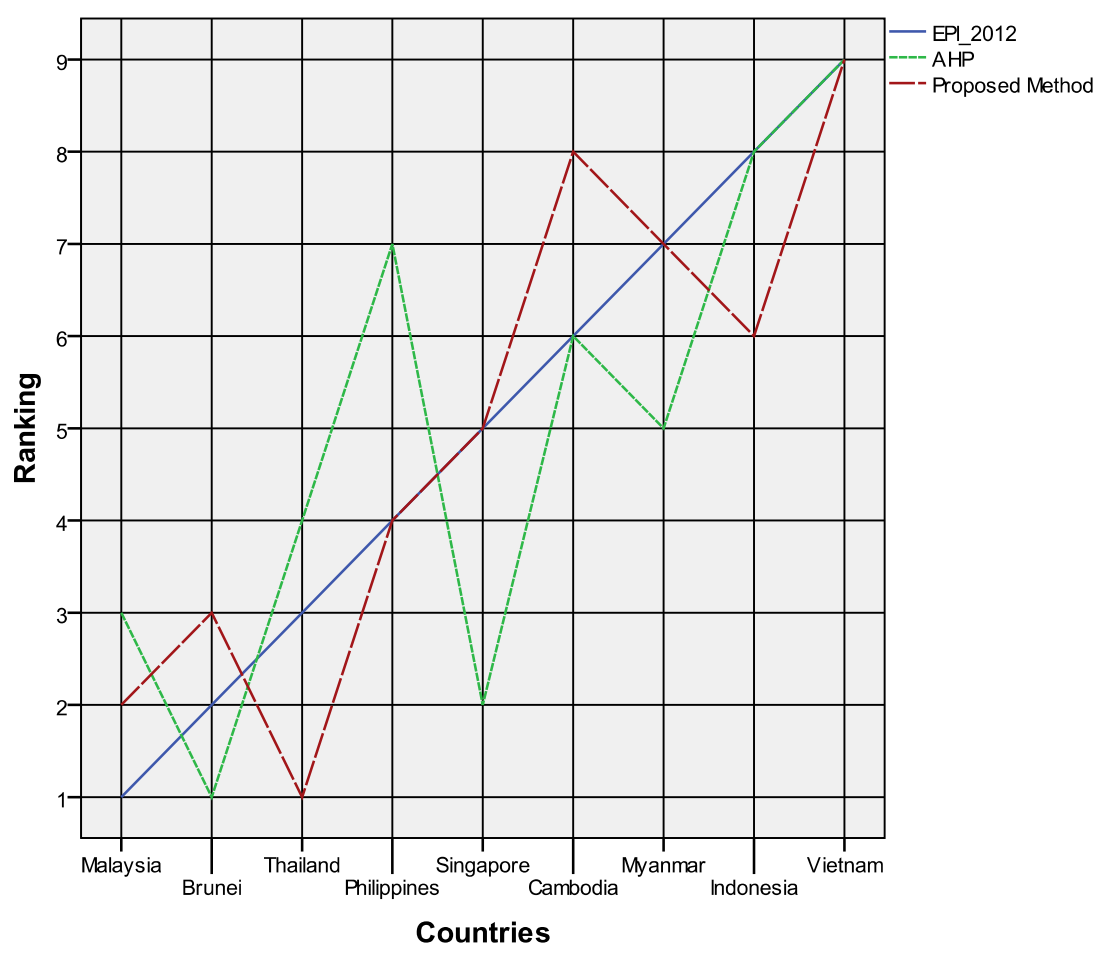

Figure 3. Ranking of EPI 2012 for ASEAN countries: comparison analysis 
It can be seen that the new ranking differs from original EPI 2012 and EPI 2012 using AHP. The original EPI indicates that Malaysia is the first among ASEAN countries in environmental performance followed by Brunei and Thailand. However, Brunei takes the first spot when AHP method is used, followed by Singapore and Malaysia. Contrarily, Thailand leads in first spot followed by Malaysia and Brunei when the calculation is made using the weighted correlation coefficients. The inconsistency in ranking can be related due to membership and non-membership of IFSs.

\section{Conclusion}

This paper has shown the capability of decision tool weighted correlation coefficient of IFSs in proposing the new ranking of EPI 2012 among ASEAN countries. The original EPI is used arithmetic mean in calculating the ten policy categories. Neglecting some extreme values was among the weakness of this simple mathematical operation. Thus, weighted correlation coefficient based on IFSs was proposed. This mathematical model was successfully proposed weights in each of category policies of environmental performance. The advantage of IFSs lies on the two-sided measurements, membership and non membership values. A new ranking of EPI among ASEAN countries show that Thailand is at the first place followed by Malaysia and Brunei. The method could be extended to other countries as this method offer an alternative measure in evaluating environmental performance. As a further research, the weighted correlation coefficient may consider the extension version interval-valued intuitionistic fuzzy sets in the calculation. It might provide a comprehensive evaluation due to its interval values thereby offer a more reliable EPI.

\section{References}

Atanassov, K. (1986). Intuitionistic fuzzy sets. Fuzzy Sets and Systems, 20, 87-96. http://dx.doi.org/10.1016/S0165-0114(86)80034-3

Belton, V., \& Gear, A. E. (1983). On a short-coming of Saaty's method of analytic hierarchies. Omega, 11, 228-230. http://dx.doi.org/10.1016/0305-0483(83)90047-6

Belton, V. (1986). A comparison of the analytic hierarchy process and a simple multi-attribute value function. European Journal of Operational Research, 26, 7-21. http://dx.doi.org/10.1016/0377-2217(86)90155-4

Burillo, P., \& Bustince, H. (1996). Entropy on intuitionistic fuzzy sets and on interval-valued fuzzy sets. Fuzzy Sets and Systems, 19, 305-316. http://dx.doi.org/10.1016/0165-0114(96)84611-2

Cui, J., \& Yu, B. (2009). The regional resource supply and environmental capacity analysis based on the ecological footprint: A case study. Modern Applied Science, 3, 96-100.

Eco Greenwares. (2009). Carbon and ecological footprints. Eco Greenwares, Retrieved from http://ecogreenwares.com/biodegradable/compostable/carbon-footprints.html

Emerson, J. W., Hsu, A., Levy, M. A., Sherbinin, A. D., Mara, V., Esty, D. C., \& Jaiteh, M. (2012). Environmental Performance Index and Pilot Trend Environmental Performance Index. Yale Center for Environmental and Policy, New Heaven.

Gernsternkorn, T., \& Manko, J. (1991). Correlation of intuitionistic fuzzy sets. Fuzzy Sets and Systems, 44, 39-43. http://dx.doi.org/10.1016/0165-0114(91)90031-K

Hersh, M. A. (2006). Mathematical Modelling for Sustainable Development. Germany: Springer-Verlag Berlin Heidelberg.

Macharis, C., Springael, J., Brucker, K. D., \& Verbeke, A. (2004). Promethee and AHP: The design of operational synergies in multicriteria analysis. Strengthening Promethee with ideas of AHP. European Journal of Operational Research, 15, 307-317. http://dx.doi.org/10.1016/S0377-2217(03)00153-X

Marchettini, N., Niccolucci, V., Pulselli, F. M., \& Tiezzi, E. (2007). Environmental sustainability and the integration of different method for its assessment. Environmental Science and Pollution Research International, 14, 227-228. http://dx.doi.org/10.1065/espr2006.12.367

Odum, H. T. (1998). Emergy evaluation. Presented at the International Workshop on Advances in Energy Studies: Energy flows in ecology and economy, Italy.

Saaty, T. L., \& Windi, Y. (1980). Marketing applications of the analytic hierarchy process. Management Science, 26(7), 641-658. http://dx.doi.org/10.1287/mnsc.26.7.641

Sadiq, S., \& Tesfamariam, S. (2009). Environmental decision-making under uncertainty using intuitionistic fuzzy analytic hierarchy process. Stochastic Environmental Research and Risk Assessment, 23, 75-91. http://dx.doi.org/10.1007/s00477-007-0197-z 
Silvert, W. (2000). Fuzzy indices of environmental conditions. Ecological Modelling, 130, 111-119. http://dx.doi.org/10.1016/S0304-3800(00)00204-0

Wan-Ismail, W. K., \& Abdullah, L. (2012). A new Environmental Performance Index using analytic hierarchy process: a case of ASEAN countries. Environmental Skeptics and Critics, 1(3), 39-47.

Yale Center for Enviromental Law and Policy and Center for International Earth Science Information Network. (2012). Enviromental Performance Index. Yale University. Retrieved from http://epi.yale.edu/epi2012/countryprofiles

Ye, J. (2010). Fuzzy decision-making method based on the weighted correlation coefficient under intuitionistic fuzzy environment. European Journal of Operational Research, 205, 202-204. http://dx.doi.org/10.1016/j.ejor.2010.01.019

Zadeh, L. A. (1965). Fuzzy sets. Information Control, 8(3), 338-353. http://dx.doi.org/10.1016/S0019-9958(65)90241-X

Zhang, L. Q., \& Cai, J. M. (2012). Eco-environmental quality assessment of Xining City based on GIS and AHP. Modern Applied Science, 6(4), 84-100. http://dx.doi.org/10.5539/mas.v6n4p84 